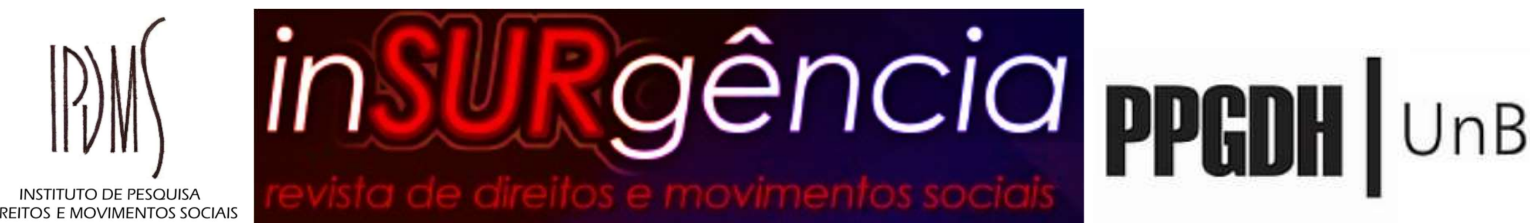

\section{A ANESTESIA JURÍDICA: A OCULTAÇÃO DO CONFLITO PELO DIREITO A PARTIR DA PESQUISA EMPÍRICA EM AUDIÊNCIAS PÚBLICAS}

\section{LEGAL ANESTHESIA: HIDING CONFLICT BY LAW FROM EMPIRICAL RESEARCH IN} PUBLIC HEARINGS

Lucas Rodrigues Sena ${ }^{1}$

Resumo: O presente artigo busca estudar a participação popular dentro do ritual da audiência pública em licenciamento ambiental. Para isso, propõe estabelecer uma análise acerca das dificuldades na pesquisa empírica de audiências e também demonstrar a validade empírica do estudo das transcrições das audiências disponíveis online. Após, analisar-se-á a audiência pública ocorrida no município de Cabo Frio em abril de 2019 de forma a complementar o estudo das transcrições. Por fim, estabelecem-se duas hipóteses: o estudo de audiências públicas como um instigante objeto de pesquisa a servir como porta de entrada a outros conflitos; e a utilização do direito como ferramenta de anestesia face os conflitos sociais.

Palavras-chave: Participação, Empiria, Audiências Públicas, Anestesia Jurídica, Dialética.

\begin{abstract}
The present article aims to study the concept of public participation starting from the ritual of public hearings in environmental assessment procedures. It proposes to estabilish a analysis about the dificulties of studying public hearings and demonstrate the validity of using online available transcriptions as an object of study. The next step will be to describe the participation in public hearing in Cabo Frio, Rio de Janeiro, to complement the study of the transcriptions. At last, we'll estabilish two hipothesys: the study of public hearins as a exciting object of research that opens the door for other conflicts; and the law's use as a tool of anesthesia to the social conflicts.

\footnotetext{
${ }^{1}$ Tem experiência na área de Ciências Sociais, desenvolvendo trabalhos sobre Antropologia do Estado. Ainda, tem experiência também no Direito, com ênfase em Direito Constitucional e Administrativo, especialmente relacionado à sistemática da interseção entre Populações Tradicionais, Estado e Grandes Empreendimentos de Infraestrutura. Mestrando em Sociologia e Direito pela Universidade Federal Fluminense, Bolsista pela CAPES. Possui graduação em Direito pela Universidade Cândido Mendes.
} 


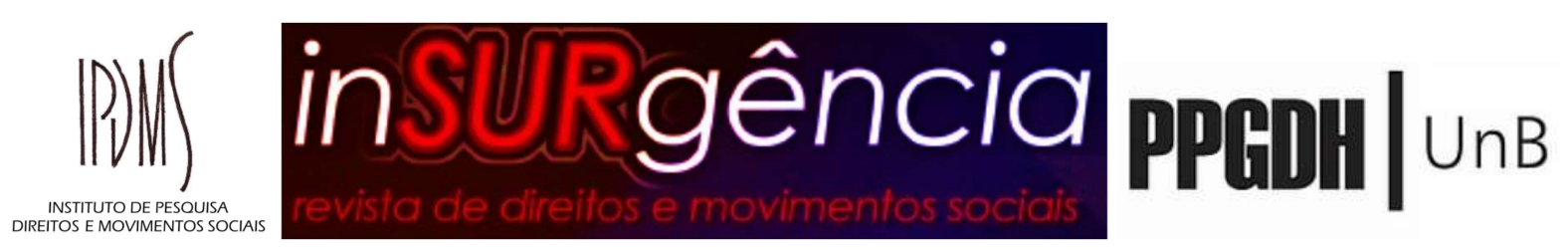

Keywords: Participation, Empiry, Public Hearings, Legal Anesthesia, Dialectics

\section{INTRODUÇÃO}

"Dos Delitos e das Penas", obra seminal de Beccaria, buscava dar à sociedade europeia de seu tempo um conceito de pena que não utilizasse a crueldade das práticas torturantes estabelecidas na união umbilical entre Estado e Igreja na Idade Média. Liminar de um novo tempo, noções como a proibição da tortura, a vinculação da pena ao ofensor, entre outras inovações, também tinha como fim situar o Direito penal dentro das luzes.

No que dizia respeito às intenções, à forma escrita da disposição jurídica, à ficção do papel, tudo estava ótimo, o criminólogo italiano teria conseguido o que almejava, havia criado uma nova forma de abordagem à relação homem-pena.

Séculos se passam, chega Michel Foucault, numa tarde de outono no bairro carioca da Gávea, Zona Sul do Rio de Janeiro, onde o sociólogo-historiador-filósofo (apesar dele mesmo ser avesso às categorizações escolares, tanto profissionalmente quanto em relação à corrente filosófica que abarcava) francês estava ministrando, entre vinte e um e vinte e cinco de maio de 1973, uma semana de palestras acerca da relação entre direito e poder que, posteriormente, seria organizada na forma do livro "A Verdade e as Formas Jurídicas” (2002).

Apropriando-se e ressignificando Nietzsche, o lotado salão nobre da PUC-Rio assiste à perplexidade de Foucault quando começa a analisar o famigerado panótico de Bentham: como foi possível que um momento teórico humanista capitaneado por Beccaria e Brissot onde novas normas foram editadas, novos livros foram elaborados, um novos ethos buscava a preponderância discursiva na sociedade da Europa continental e, mesmo com a criação deste mundo ficcional, o direito praticado pela época tinha, ao contrário, criado seu oposto: o panótico e a sociedade de vigilância?

Partindo desta instigação, o presente trabalho busca analisar empiricamente um fenômeno jurídico da audiência pública no âmbito do licenciamento ambiental tendo como enfoque o problema metodológico de se a normatividade voltada à participação popular no licenciamento ambiental é efetivada na prática ou se, analogamente ao construído por Foucault, não só o direito em tese não é aplicado mas que, pior ainda, acaba produzindo seu contrário. 


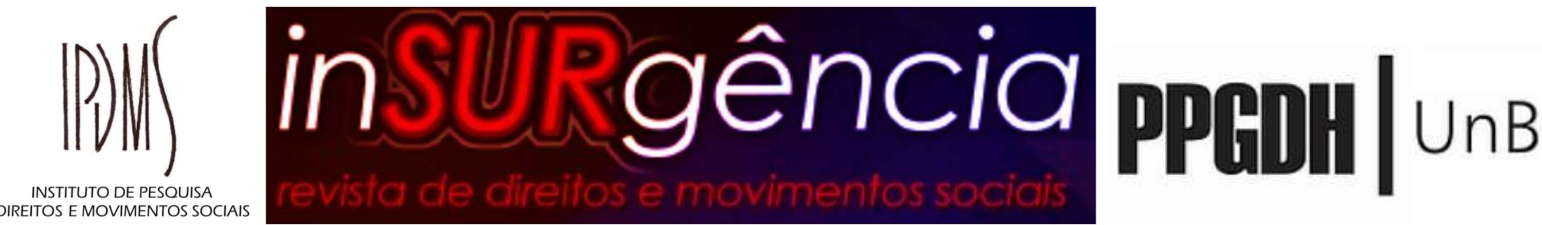

\section{TRANSCRIÇÃO COMO OBJETO DE ANÁLISE}

O primeiro ponto de dificuldade que a análise empírica de uma audiência pública traz ao pesquisador se dá pela sua própria natureza transitória como um ato dentro de um processo, ou seja, um acontecimento social dotado de significado que acontece numa determinada temporalidade e espacialidade. Em outras palavras, a audiência começa e termina no mesmo dia, muitas vezes não tem a divulgação necessária e, em outras, quando a divulgação acontece a mesma é muito próxima do evento em si, impossibilitando que o pesquisador se planeje a tempo de comparecer.

Outro ponto a ser considerado é a própria interiorização dos empreendimentos com maior impacto ambiental: pela própria escassez de espaço e recursos nas cidades, os procedimentos encaixados como ambientalmente impactantes acontecem, na maioria das vezes, em cidades do interior, lugares afastados dos grandes centros o que aumenta o problema do tempo, planejamento e, principalmente, o custo que uma pesquisa neste sentido traz ao pesquisador.

A pesquisa empírica que está a chegar a um ano de duração mostra também que, ao contrário do que inicialmente imaginado, audiências públicas dentro de procedimentos de licenciamento ambiental não ocorrem tantas vezes quanto esperado ou, se ocorrem, entram no espaço da não divulgação.

Um ponto pode explicar este último aspecto: Conforme disposição constitucional (Artigo $225, \S 1^{\circ}, \mathrm{VI}$ ), todo empreendimento causador ou com potencial de causar impacto ambiental deve passar pelo crivo do procedimento do licenciamento ambiental mas, ao revés, nem todo Estudo de Impacto Ambiental - EIA, tem na audiência pública uma de suas partes, sob a justificativa de que esta deve ser utilizada quando o impacto for de grande porte.

Para o empreendimento, apesar da posição institucional de alguns agentes, como veremos posteriormente, a audiência pública não traz nenhum "benefício", pelo contrário: a audiência pública é o momento final de um subprocesso onde o empreendedor contrata uma empresa de consultoria para elaborar um Relatório de Impacto Ambiental - RIA, defendendo a possibilidade do empreendimento naquele lugar e vem a público apresentar os resultados para a sociedade onde, em tese, esta deveria ter a possibilidade de serem ouvidas suas dúvidas e sugestões face o órgão licenciador, que terá no seu representante o Presidente da mesa. 


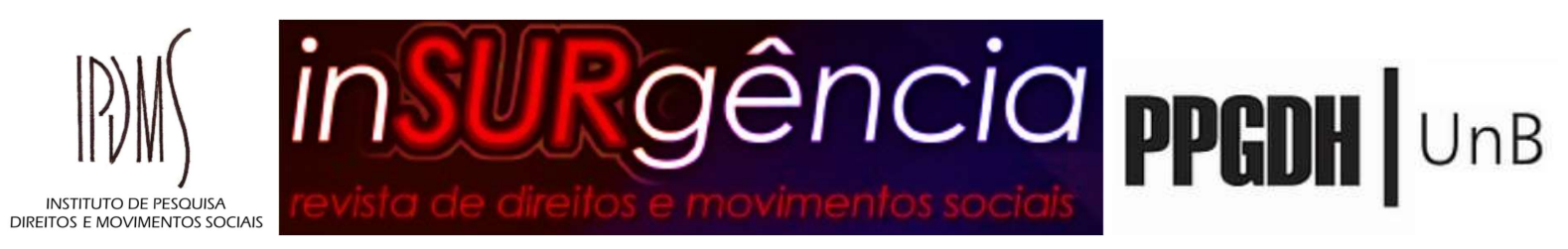

Project-splitting é o nome dado na literatura estrangeira para o caso em que a empresa que busca o licenciamento em um país que utiliza uma forma descentralizada de exame calcada na magnitude do projeto, ou seja, empreendimentos de grande impacto seriam licenciados pelo órgão nacional, os de médio pelo estadual e os de baixo pelo Município/Condado (ONU, 2019), divide o empreendimento principal em várias partes de forma a "fugir" do órgão nacionalizado que, normalmente, tem maior estrutura de investigação e é mais rigorosa na concessão da licença para a operacionalidade daquele.

Uma hipótese que pode ser trabalhada dentro desta ideia de escassez de audiências públicas em EIA, além de questões outras como recessão econômica e incertezas políticas, seria pela possível prática de project-splitting a diminuir o número de licenciamentos de grandes empreendimentos.

Poucas audiências públicas acontecem e, quando acontecem, são afastadas de grandes centros urbanos ou em outros estados. Além disso, a escassez de financiamento público faz também que mesmo que elas acontecessem em médias distâncias seu custo impossibilitaria o trabalho do pesquisador. A título de exemplo, só o gasto para acompanhar uma audiência na cidade de Cabo Frio, região dos Lagos do Rio de Janeiro e distante duas horas e quarenta minutos de ônibus, adicionando custos de hospedagem e estadia de dois dias e uma noite custa por volta de um terço da bolsa de mestrado para um pesquisador residente no mesmo estado do Rio de Janeiro.

O risco acompanhado é de a pesquisa em audiências públicas ambientais ficar dotado de uma certa aleatoriedade: o pesquisador teria de esperar a "sorte" de acontecer uma audiência próxima durante o tempo que ele tem disponível pra pesquisa. Este fato em si faz com que o número de pesquisas sobre audiências públicas diminua bastante na medida em que faz inoportuno vincular uma dissertação de mestrado, por exemplo, ao estudo do instituto audiência pública.

Com este problema em mente, construímos outra hipótese: o problema do estudo da audiência pública pode ser resolvido, em parte, pelo uso de transcrições disponíveis on line junto aos órgãos licenciadores. Os procedimentos de licenciamento ambiental são públicos e, em conjunto com a informatização dos procedimentos estatais, as atas das audiências passaram a ficar disponíveis ao público.

Em alguns grandes empreendimentos, além da transcrição em si da audiência (o que, claro, pode causar alguns problemas como algumas inconsistências de narrativas, perguntas e 


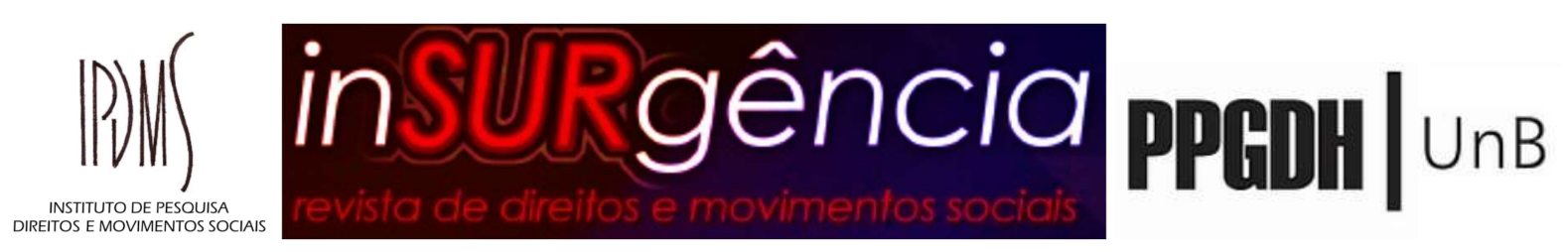

respostas incompletas em alguns casos, dentre outros), o arquivo $p d f$ acompanha também imagens relacionadas à divulgação da mesma, como pôsteres, cartazes, além da ficha dos ônibus fretados para transporte gratuito de quem saía a partir de alguns pontos específicos.

Para testar essa hipótese, busquei online a transcrição de uma audiência ocorrida no município de Niterói/RJ, lugar onde curso o mestrado em Sociologia e Direito da Universidade Federal Fluminense - UFF, e que se relacionasse com a temática dos pescadores da Baía de Guanabara. A ideia deste binômio é, por um lado, tentar suprimir parte da impessoalidade do texto frio a partir da proximidade com o local de acontecimento de forma a facilitar a abstração de categorias analíticas utilizadas durante o rito e, por outro, buscar o enfoque de uma população tradicional, com as dificuldades e desafios que são impostos e analisar eventual distorção jurídica a partir da disparidade de forças entre, por um lado, uma associação local de pescadores e, por outro, um grande empreendimento de petróleo e gás.

“O ponto cego, o outro vê.” Heinz Van Foerster (1981) apud Marcelo Neves (2014)

Etnografia e Antropologia são utilizados praticamente como sinônimos. Desde Malinowski, o "batismo de fogo" de todo antropólogo seria a elaboração de uma etnografia, um trabalho de campo onde o pesquisador estaria inserido na realidade local, buscando apreender as categorias e modos de viver dos pesquisados, muitas vezes a partir da observação participante (WRIGHT, 2005)

Como sabido, os primórdios da antropologia praticada no atlântico norte (TROUILLOT, 2011) tinham como maior objeto a observação do "outro", de uma sociedade "primitiva". Neste sistema, a entrada no campo de um pesquisador vindo de um país central acaba por ser auxiliada pelas relações de poder intrínsecas ao poder simbólico das instituições representadas.

Laura Nader, em 1972, propõe uma virada epistemológica acerca do objeto a ser analisado a partir do método etnográfico: ao invés de se observar o outro, passar a produzir pesquisa a partir da observação da própria sociedade norte-americana, encarar seus próprios pressupostos (ALEXANDER, 1987) e preconceitos. Não só olhar para dentro, mas também passar a observar as corporações que regem a vida no capitalismo tardio: "corporations feed our children, clothe our children, and help determine their genetic legacy." (NADER, 1980)

Os métodos utilizados para estudar populações em lugares longínquos poderia seria tão eficiente quanto na etnografia das práticas de um executivo-chefe? Como participar da tomada de decisão de um escritório especializado em lobby de grandes corporações (NADER, 1972)? 


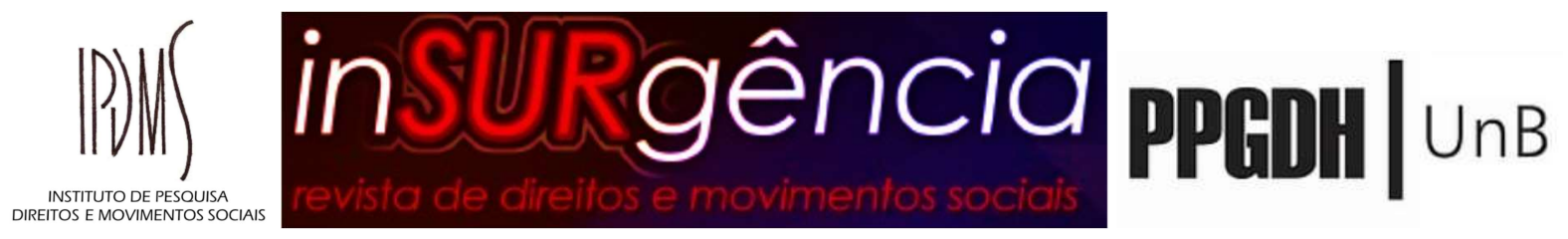

Em resposta à essas perguntas, Nader estabelece que, apesar do valor que a observação participante tem para a antropologia, devem ser buscadas novas técnicas etnográficas para o estudo deste novo objeto. Entre outros exemplos, a professora norte-americana estabelece o valor, por exemplo, da etnografia documental, processos judiciais, entrevistas, não separadamente, mas em conjunto, estabelecendo uma etnografia de quebra-cabeças, juntos as peças do puzzle formado pelas instâncias de poder.

Vinte anos após a proposta do "studying up", Hugh Gusterson (1997) aborda como tal proposta envelheceu e como poderíamos adaptá-la às novas demandas que começavam a aparecer no liminar do milénio, especialmente no que diz respeito à metodologia a ser utilizada.

Ratificando as dificuldades de se estudar o poder, propõe o "engajamento polimorfo", significando “interagir com informantes através de um número de lugares dispersos, não apenas em comunidades locais, e as vezes de forma virtual; significa coletar data ecleticamente de uma ampla gama de fontes em várias maneiras.” (1997)

Após procurar pelas características explicitadas acima, encontrei na internet uma audiência ocorrida no mesmo ano do início da pesquisa, 2018, no município de Niterói, acerca do projeto "etapa 3" de exploração de Petróleo e Gás na Bacia de Santos, dentro do conhecido "Pré-sal".

Lugar central tem os discursos dos agentes licenciadores. Sempre que há um confronto, ou alguma pergunta/manifestação que ultrapasse os limites do ritual, ou seja, uma manifestação que seja mais combativa, uma manifestação que traga fatos novos, uma manifestação que aborde certos pontos centrais do empreendimento, surge uma espécie de "totem": a repetida expressão "sua sugestão será levada em consideração pelo IBAMA".

Outros pontos também são realçados pela análise da transcrição: um exemplo seria o conjunto de estruturas e processos físicos, humanos e linguísticos que servem para, na leitura do documento jurídico, dar a aparência de que tudo está em "um bom caminho". No papel, tudo está perfeito: ônibus são fretados para levar as pessoas à audiência, empresas de promoção de eventos são contratadas, lanches são oferecidos, anúncios em associações de pescadores são colocados, ao final de cada pergunta, o presidente da mesa, representante do órgão licenciador, sempre pergunta se a pessoa está satisfeita com a sua resposta. No papel não há conflito.

Vale a pena pontuar como sempre há a resposta de que a pergunta será levada em consideração, mas como confirmar isso? Não há na sistemática da audiência pública nenhuma 


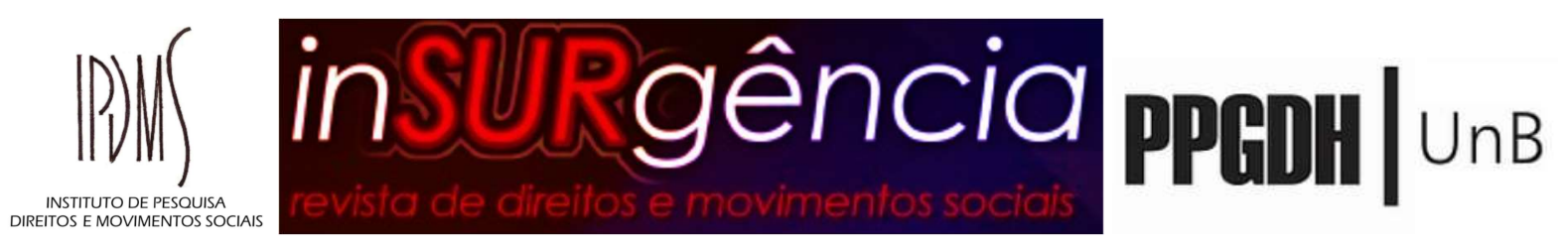

forma de fiscalização do agente estatal, tudo ficando na aceitação ou não da "palavra" do licenciador.

À primeira vista, tudo está lindo e belo, mas além da própria desconfiança que é traga pela constatação de um procedimento tão "anestesiado" pela ação do órgão licenciador em uma disputa completamente desigual, alguns fatores também são indiciários da falta de real efetividade da audiência pública: além da indicação que ônibus são fretados para levar as pessoas interessadas à audiência, também são colocados as listas de pessoas que utilizaram cada ônibus saltando aos olhos como diversos ônibus, sua grande maioria, saiu de alguns pontos, notadamente associações de pescadores, com nenhum passageiro, ou um, dois, três, no máximo. O ônibus com maior número não passava de quinze pessoas.

Por que as pessoas diretamente atingidas por um empreendimento tão grande quanto o pré-sal, tão conhecido e já dentro do imaginário popular, e já tão precarizadas, simplesmente não comparecem ao único local que, em tese, ocorreria um ritual completamente voltado para a sua participação?

“Cum grano salis", expressão latina que quer dizer, basicamente, com uma pitada de sal, ou seja, com ponderação, relativizando.

A transcrição de uma audiência pública pode ser considerado um método de pesquisa apto para estudar conflitos socioambientais? A resposta seria sim, e não. A transcrição da audiência confere acesso a algo que, não fosse este expediente, seria basicamente impossível de se ter apenas a partir de outros métodos, como entrevistas. No caso da audiência do projeto “etapa 3", o arquivo possui mais de 250 páginas divididos na transcrição em si e documentos anexos.

Assim, a transcrição confere uma rica base de dados que podem ser utilizadas como porta de entrada para o mundo do licenciamento ambiental na medida em que um olhar cuidadoso aos seus termos pode indicar novos problemas de pesquisa que são escamoteados pela linguagem anestesiada do direito.

Especialmente no segmento de perguntas e respostas, a transcrição consegue passar alguns dramas pessoas, algumas histórias que merecem ser contadas, mas que são atomizadas pelo tamanho do empreendimento. Cada pergunta, cada resposta, cada tréplica, abre a possibilidade de um programa de pesquisa específico.

Por outro lado, apesar de ser possível "pescar" conflitos a partir de seu relato, a transcrição tem um limite, qual seja, aquele da abordagem impessoal do direito. De uma certa 


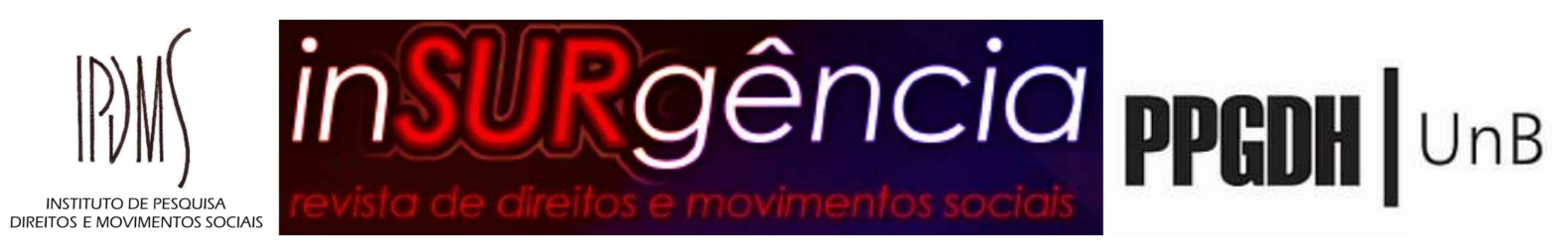

forma, toda a transcrição possui uma eminência parda jurídica, sua razão de ser está numa letra de lei que faz com que o órgão licenciador faça mover sua engrenagem técnica no sentido de elaborar uma transcrição.

O procedimento passa a ser todo calcado por categorias jurídicas, não somente nas expressões utilizadas pelo órgão licenciador, mas também pelas condicionantes que o direito pressupõe, ou seja, as respostas devem ser dadas de uma certa maneira pois é com esta maneira que o procedimento estará de acordo com a Lei.

Partindo desta percepção, um estudo que se restringisse apenas à transcrição ficaria incompleto, por isso que sua abordagem deve seguir o pensamento do engajamento polimorfo na medida em que este instiga a associação de diversos métodos. Assim, a transcrição é incompleta, mas sua razão de ser na pesquisa científica não é, nem deve ser, constituir o único meio possível, mas sim um dos meios possíveis que deve ser utilizado em conjunção com outros.

Sua riqueza, instiga a busca por novas formas de abordagem, novos objetos empíricos dentro desse sistema. Ato contínuo, a vontade de contar histórias, de entender o conflito, de mostrar e se ver nas pessoas ali presentes, traz a necessidade de estar pessoalmente numa audiência para que seja possível entender melhor as disputas de significado que acontecem naquele ritual.

\section{COMPLETANDO O OLHAR A PARTIR DA OBSERVAÇÃO EMPÍRICA}

Kelly Silva, ao falar sobre a "cracolândia", em São Paulo, instiga o leitor a partir da constatação de como aquele local que externamente é visto como uma "coisa" monolítica, na verdade é um extremamente complexo fenômeno social com inúmeros agentes e instituições em posições, estatais ou privadas, diferentes interagindo incessantemente.

A mesma percepção acontece a partir do comparecimento numa audiência pública. Vaise na audiência com aquele tipo-ideal de que só teriam lá pescadores (unificando uma categoria muito complexa, cheia de meandros, conforme percebido na audiência) e, em outro lado, o empreendimento.

Nada estaria mais errado do que isso.

Assim, decidi ir no município de Cabo Frio/RJ para colocar à prova a percepção extraída da análise das transcrições. O primeiro ponto que chama atenção é o tamanho do aparato de 


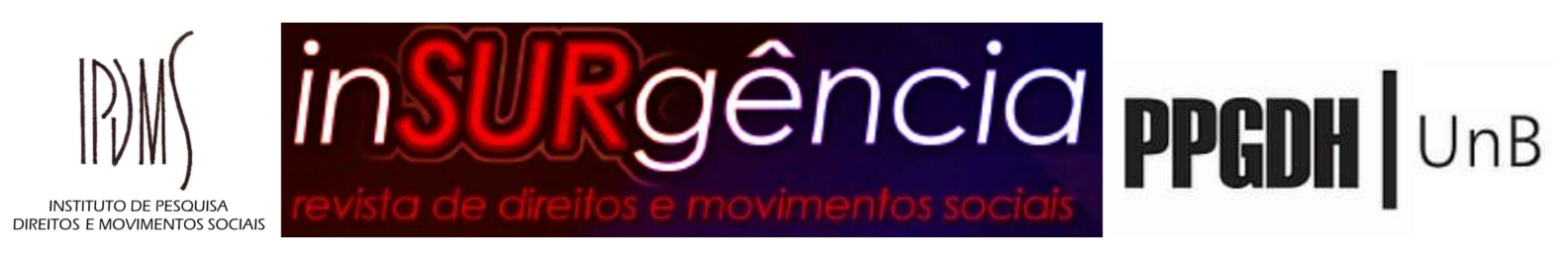

legitimação: hotel de luxo, contratação de empresa dedicada à promoção de eventos. Não à toa, obviamente, todo o aparato serve para transparecer o poderio socioeconômico dos agentes organizadores.

O que mais impressiona, entretanto, é quando começa a audiência e se percebe que aquela visão monolítica de quem seriam as pessoas que assistem a audiência pública é completamente errônea na medida em que são inúmeros movimentos sociais, instituições, atores privados, atores públicos, atores privados com financiamento público, instituições de pesquisa, associações com relação à sistemática das medidas compensatórias, pescadores, remanescentes de quilombos, movimentos representativos de municípios, forças armadas, todos ao mesmo tempo de certa forma conectados e separados, em constante ebulição.

A partir daí, a ideia era além de estudar o aparato e as disputas de significado relacionadas à audiência, perguntar, entrevistar as pessoas que participavam do procedimento para saber qual a percepção das pessoas que estavam diretamente afetadas pelo empreendimento.

Sobre este, consistia no projeto de aumento na exploração de petróleo e gás no Campo de Peregrino, situado próximo ao município de Cabo Frio, a partir da implementação de uma nova plataforma de extração a ser feita pela empresa norueguesa Equinor, anteriormente chamada de Statoil.

Voltando para audiência, utilizou-se de uma metodologia de pesquisa participativa a partir de entrevista semi estruturada de forma a evitar o posicionamento do pesquisador como uma espécie de tutelador da população tradicional, alguém que fosse dizer para aquelas pessoas quais deveriam ser suas sensibilidades. Pelo contrário, minha intenção naquele momento era dar voz àquelas pessoas e contar suas histórias, suas experiências naquela situação.

Dentro dessa ideia, durante a audiência fiquei atento ao que as pessoas que estavam ao meu redor falavam, quais eram suas reações, além de, durante um dos intervalos da audiência, entrevistar um líder associativo dos pescadores, coletando, entre outras expressões, algumas como: "Você acha que o IBAMA vai canetar uma coisa dessa?"; "Já liberamos para eles, já viemos à audiência."; "Fazer uma audiência com a chefia, aqui já tá ganho (para a empresa)."; "Isso só funciona se o MP estiver presente."

Terminado o primeiro segmento onde a empresa, órgão licenciador e empresa de consultoria apresentam o projeto e o relatório, sob a presidência do órgão licenciador, começa 


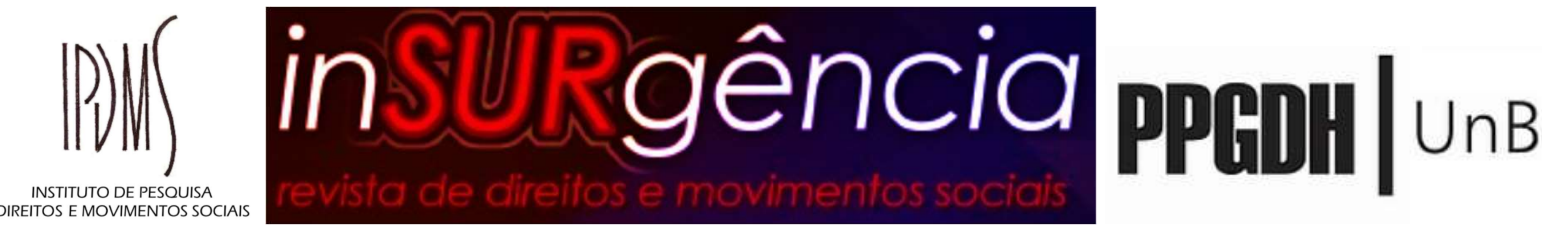

um breve período de coffee-brake onde são distribuídos os "kit-lanches" para quem quiser, além de café e biscoitos.

O momento pareceu propício para entrevistar uma daquelas pessoas que estavam sentadas à minha frente, tentar elaborar a partir das conversas que tinha ouvido antes e da percepção geral da audiência. Sendo assim, entrevistei um participante que após se identificou como presidente de uma associação de pescadores de um município da região.

O que era pra ser uma pesquisa sobre a audiência isoladamente acabou se tornando um rico relato acerca das dificuldades que os pescadores da região da Baía de Guanabara atualmente encaram e como essas dificuldades são expressadas de várias formas. O primeiro ponto discutido foi sobre o caso da "pesca fantasma" nas suas duas formas:

A primeira acontecendo quando barcos de apoio partem a rede de pesca, levando-a para outra localidade fora da área de controle dos pescadores e, com isso, "a rede não para de pescar", captando peixes mas sem que o pescador possa chegar ao local onde isso está acontecendo, ou seja, há um duplo prejuízo: ao mesmo tempo em que o pescador perde seu material e a possibilidade de auferir renda com ele, de pescar com ele, também perde quando o peixe não pode mais chegar ao local onde está o seu equipamento haja vista que o equipamento rompido subtrai da sua esfera de possibilidade o pescado da região, face sua retirada pela rede fantasma.

A segunda forma é a pesca por aproximação: o pescado é atraído para o redor dos FPSO's (os barcos que fazem, entre outras coisas, a coleta do que é extraído pelas plataformas) e das plataformas e, face a proibição instaurada pelas NORMAN's 07 e 08, o pescador não pode chegar nele para fazer sua pesca, o que é especialmente nocivo, segundo coletado em entrevista, para culturas como a pesca de atum. Lembrando que o empreendimento objeto desta audiência pública consistia na instauração de uma terceira plataforma, ou seja, seria uma terceira acessão que traria consigo nova limitação de aproximação de 500m ao seu redor.

Tratando acerca da área disponível para pesca, disse que de toda Baía de Guanabara, apenas 3\% é liberado para a exploração do pescador e, além disso, o que é mais impactante, cada barco de apoio de empreendimento de exploração de petróleo traz, segundo o entrevistado, a limitação de 150 metros ao seu redor.

Em outro ponto no Rio de Janeiro, a classe dos pescadores abrange, segundo o entrevistado, vinte e quatro mil pescadores, e dois mil só na Associação de Pescadores de São Gonçalo, representada pelo entrevistado, o qual, então, pergunta se não teriam significância (dos pescadores) para a sociedade. Este dado é importante para ser cruzado com a informação 


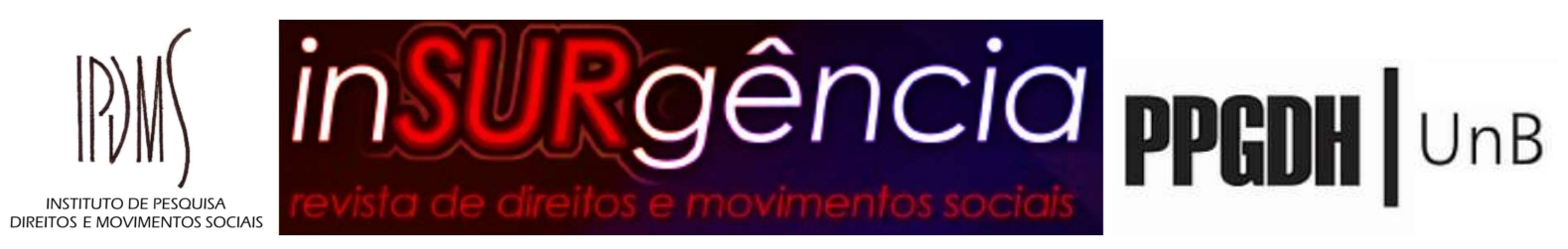

da transcrição onde esta mostrava a baixíssima quantidade de pessoas que saíram das associações em direção à audiência. Menos de vinte pessoas em um espectro de dezenas de milhares.

Além da impossibilidade de pesca, ocasionada tanto pela "pesca-fantasma" quanto pela poluição causada, em grande parte, pelos grandes empreendimentos de extração de petróleo, o "Estado do Rio de Janeiro não tem peixe, chegam, inclusive, a trazer (sardinha) do Marrocos por não ter peixe no Rio de Janeiro".

Terminando a conversa, pergunto se há a possibilidade de algum contato direto com o Ibama, o qual foi respondido com perplexidade, inclusive exemplificando como se fosse uma relação entre empregado (pescadores) e patrão (Ibama) e também com um exemplo até cômico: Se um ator tenta conversar com o Silvio Santos, o que acontece? Vão falar pra ele: "sai daqui"."

Esta última frase em especial é central para extrair a percepção de que não, a audiência pública não constitui na prática um meio efetivo de participação. Juridicamente falando, a questão principal é desdobrar a participação em duas vertentes, formal e material: Formalmente falando, os pescadores integram o aparato de legitimação. Eles "podem" falar, suas perguntas são colocadas nas transcrições e respondidas pelos membros da mesa. A questão é o quanto essas perguntas são efetivamente levadas em consideração dentro do aparato.

"Não adianta nada poder falar e não ser ouvido." - Representante associativo

Talvez a questão seja o fato de que o instituto da audiência pública, como foi elaborada, não se constitui num instrumento de ação, e sim de participação. A audiência pública não é uma real parte do processo de licenciamento e sim uma espécie de apêndice do procedimento onde o órgão licenciador preside o ritual onde é apresentado para a sociedade os resultados preliminares do empreendimento, e não onde a sociedade leva ao órgão licenciador suas questões. Claro que ao falar "sociedade" estamos simplificando para fins de análise um conceito que já desconstruímos a partir da pesquisa empírica e a percepção da complexidade do ritual e diversidade de seus agentes.

Voltando às populações tradicionais, a descrença no instrumento de participação é tamanha que o presidente de associação que falou conosco estava apenas com mais dois colegas na audiência, enquanto que sua associação teria três mil associados, a de outro representante associativo teria cinco mil, cada uma circunscrita a um município fluminense. A percepção tirada a partir dos documentos anexos à transcrição daquela audiência em Niterói acabou se confirmando na pesquisa empírica, especialmente a lista de presentes. 


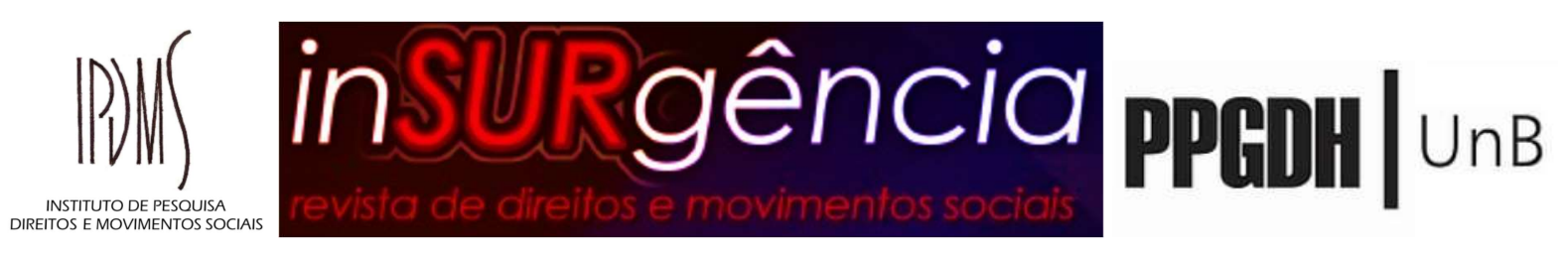

Com o fim do "coffee break" começou a sessão de perguntas e respostas, podendo ser extraído dentre os diversos movimentos participantes uma espécie de "grito silencioso": mais do que seu trabalho, eles estavam lutando pelas suas próprias vidas, pela cosmologia que geracionalmente foi criada a partir da conjugação entre o seu trabalho e a terra que estavam situados, percebendo como se tornaram precários.

"Look at it this way. A man takes a job, you know? And that job - I mean, like that That becomes what he is. You know, like - You do a thing and that's what you are." - (TAXI, 1976).

Outro ponto a ser trabalhado é como a audiência na verdade acaba por encerrar uma contraditoriedade entre o âmbito do empreendimento em si e o âmbito da exploração econômica regionalizada: além do totem "sua pergunta será salva e será levada em consideração na concessão ou não da licença", outro muito utilizado para que uma eventual pergunta não seja respondida é dizer que aquela não se refere ao empreendimento em si, que aquela audiência só tem como escopo o empreendimento do Campo de Peregrino, no caso trabalhado, e falar sobre questões "macro" seria fugir do escopo daquele ritual.

A contraditoriedade parte do fato de que não há como desvincular o estado de precariedade causado aos pescadores no sistema de exploração macro, onde estão inseridos. Muitas vezes a diferença entre o campo de exploração "a" e o "b" é uma fronteira artificial estabelecida pelo ente estatal, e os perigos causados à população tradicional não se configura apenas por um empreendimento, mas pelo todo considerado. Em outras palavras, uma coisa é a análise isolada dos efeitos da pesca fantasma ao redor da plataforma de exploração, outra coisa é o efeito desta plataforma em conjunto com as outras plataformas que colonizam às águas fluminenses.

Em mais um exemplo de desconstrução de pressupostos pela pesquisa empírica, o trabalho de pesquisa na audiência e as respostas dadas pelo órgão licenciador mostram como pode ocorrer no Brasil uma espécie de "project splitting" invertido: ao invés do empreendimento dividir suas fases, é o órgão licenciador que divide a abordagem em relação aos empreendimentos.

Mais do que a entrevista feita com os pescadores, as perguntas feitas, a reação futebolística quando de algumas manifestações, é o conjunto de todos esses aspectos, a sensação coletiva de desesperança, o grito da morte de um estilo de vida, uma que, conforme fala de uma representante do movimento "Mulheres Pescadoras", ajudou a formar seus filhos e de 


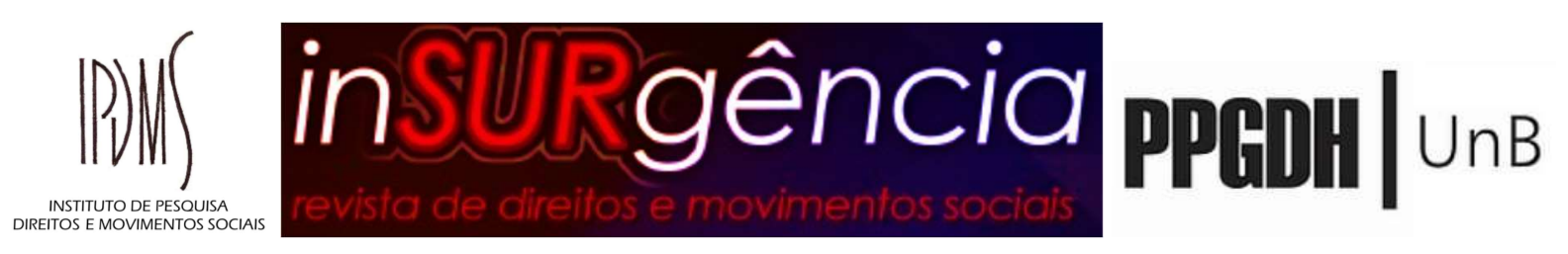

familiares, tudo isso que demonstra a incompletude do instituto da audiência pública como ferramenta de participação popular.

Segundo as experiências relatadas no campo, há a sensação de união entre o órgão licenciador e o agente empreendedor, inclusive ressaltada pela posição física entre ambos e pelo fato de que, em alguns momentos, a pergunta dirigida ao empreendedor e a empresa de consultoria ser respondida pelo agente licenciador, e vice-versa. Consolida-se um ethos de "nós" contra "eles", também relatado no trabalho de Santos, Ferreira e Penna, quando de sua análise do empreendimento Rio-Minas (2018).

Podemos identificar uma característica compartilhada pela análise documental, em especial a transcrição, e a análise in loco: ambas instigam o pesquisador a buscar novas informações e novas abordagens na análise do objeto. Dessa forma, a questão não é encarar que a pesquisa empírica presencial como uma "evolução" da transcrição e que o acompanhamento daquela exaure o tema. Pelo contrário, a empiria mostra como cada metodologia é rica em elementos e devem ser utilizadas em conjunto, e não hierarquicamente.

Qual seria a posição de um agente estatal sobre todas as contradições que o trabalho de campo apresenta? Ato contínuo, percebi a necessidade de conversar com algum agente do Ibama, ouvir a posição de alguém "de dentro", até mesmo por motivo de rigor científico e buscar falar com todos os "polos" daquele complexo sistema, apesar do fato de, como já ressaltarmos, nenhuma categoria com pretensão de completude serve para definir os agentes que estão numa audiência.

Quem seria o Estado? O órgão licenciador (naquele caso, o IBAMA); a Marinha do Brasil (lá presente em virtude de sua atuação na Capitania dos Portos); os órgãos de pesquisa estaduais voltados à proteção ambiental; representantes do executivo municipal, mormente o secretário de Meio Ambiente, em conjunto com outros atores políticos; as ONG's que participam da questão ambiental a partir de sua instituição decorrente do estabelecimento pelo Estado de medidas compensatórias? Digamos que fosse o Ibama, com quem falar, um servidor de carreira com mais de uma década de atuação licenciatória ou um ator com maior grau hierárquico mas que está no cargo em virtude de indicação política, tendo pouca experiência?

Quantos Estados existem dentro do Estado; quantos "Ibamas" existem dentro do "Ibama", quantos pescadores dentro dos pescadores? Ao final, a percepção é que a utilização de uma categoria como "Estado" na verdade acaba mais por esconder a complexidade da disputa de significado do que dar luz aos processos que acontecem naquele momento. 


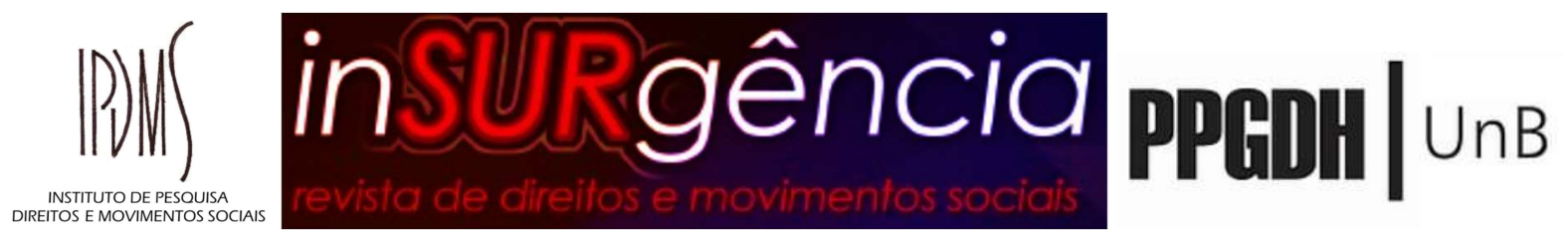

"Se eu pudesse mudar alguma coisa no licenciamento, seria a criminalização do agente do Ibama" - Entrevistado, agente do Ibama.

No mês seguinte consigo fazer uma entrevista por telefone com um agente do Ibama, já esperando que, conforme Laura Nader, a coleta de informações seria muito mais difícil do que quando feita junto a alguém pertencente a alguma população tradicional.

Entretanto, como a mesma antropóloga norte-americana esclarece, o fato de ser mais difícil a coleta de informações junto àquelas pessoas no "topo da pirâmide", não faz com que seja impossível, devendo o pesquisador utilizar de outras fontes de informação para buscar algo que não seja a já pública posição institucional.

Já tendo sido feita uma revisão de bibliografia sobre o tema (BRONZ, 2016), além de conversas com colegas pesquisadores com mais experiência na sistemática ambiental, alguns discursos "plásticos" passam a serem observáveis mais facilmente. No caso de uma audiência pública, o famoso "a audiência é o local onde a comunidade tem a possibilidade de influenciar no empreendimento, de trazer suas reclamações, e o órgão licenciador utiliza dessas interações quando do julgamento do procedimento administrativo", é um grande indicador de uma fala institucional.

Sendo assim, a entrevista se desenrolou no sentido de buscar algum ponto que fugisse da institucionalidade e que desse voz a alguma percepção real do agente, algo que demonstrasse estar ele de acordo ou em desacordo com a sistemática, novamente utilizando de perguntas abertas e atentamente observando as respostas e o que era falado, mas não dito, ou seja, o que o agente realmente queria dizer com algumas respostas de forma a abstrair um novo caminho de perguntas.

Assim, após algumas respostas protocolares a respeito do instituto da audiência pública após ser perguntado sua opinião acerca do instituto, inclusive com as já citadas respostas sobre "a importância da audiência pública e ser este o momento em que a sociedade tem a possibilidade de conhecer o empreendimento e auxiliar o órgão licenciador na concessão ou não da licença", seguiu-se outra pergunta mais aberta: "se você pudesse mudar algo na audiência, o que seria?" Como resposta, o agente asseverou que "O maior problema da audiência é a criminalização dos agentes do IBAMA pelo Ministério Público". 


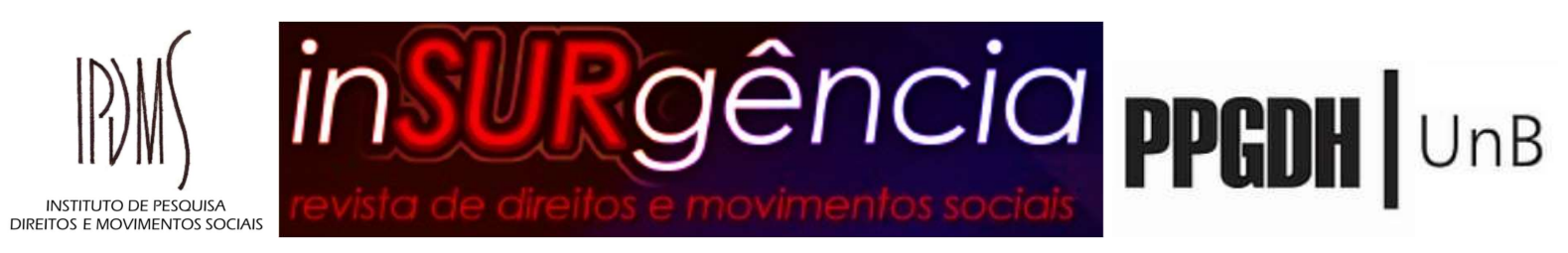

\section{CONCLUSÃO: A ANESTESIA PRODUZIDA PELO DIREITO}

Mais uma vez o trabalho empírico acaba destruindo as pré concepções do pesquisador e até mesmo do senso comum. Aquela visão retirada do campo de que haveria uma espécie de união entre empreendedor e Estado na verdade acaba por ser uma análise que não acompanha a complexidade do fenômeno estudado. Não que não possa haver essa institucionalização da atuação estatal no licenciamento público a partir da observada maior "afinidade" entre os agentes licenciadores e os empreendedores do que em relação às pessoas diretamente afetadas pelo procedimento, mas sim que a audiência pública acaba sendo a porta de entrada para fenômenos muito mais complexos.

Dentro da ideia de quem seria o Estado, as disputas de significado entre o Ministério Público e o órgão licenciador trazem para o jogo de poder a presença da legislação penal, seu caráter inquisitorial e força de coação sem igual dentro do ordenamento brasileiro, o que acaba sendo cruzado com um relato coletado no trabalho de campo, feito por um pescador, que "Isso só funciona se o MP estiver presente".

A questão trazida pelo relato do agente do Ibama é a possível desconstrução da visão "vilanizada" do agente estatal na medida em que o medo da criminalização faz com que o agente não possa desautorizar o licenciamento por conta do fato de que o técnico do MP teria feito um parecer no sentido de aprovação, e vice versa. Segundo foi passado, o agente do Ibama fica coagido a seguir o relatório do agente do Ministério Público, sonhando "que o pescador traga a informação de que naquele lugar tem um animal x que esteja em risco de extinção e que então não possa ter o empreendimento".

Claro que isso pode ser levado pelos dois "lados" (que em tese deveria estar dentro do mesmo "lado", formando quase uma dialeticidade da administração pública, acoplamentos e desaclopamentos), ou seja, acontecer um procedimento em que o órgão licenciador quer aprovar o licenciamento e o MP não, e vice-versa. Entretanto, o interessante neste caso é como o dar voz ao "objeto" da pesquisa, em todos os âmbitos, mostra uma complexidade que é muito maior do que aquela observada numa transcrição de audiência.

No final, a cada entrevista novos agentes vão sendo apresentados, o que era quase um jogo de futebol acaba sendo uma complexa rede neural (TAUSSIG, 2006) com inúmeros agentes nacionais, internacionais e transnacionais, com todos os agentes numa espécie de desesperança quanto à proteção ambiental. Os pescadores sabem que seu modo de vida está nos 


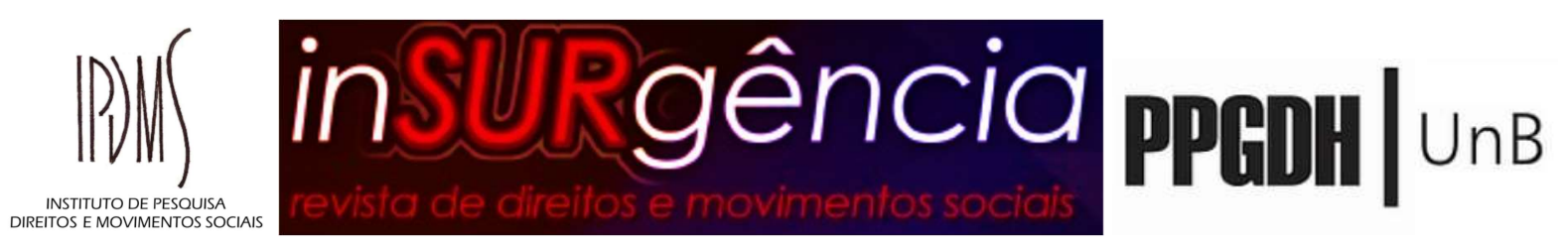

últimos suspiros, seus filhos não querem ser pescadores, pelo contrário, acabam tendo uma ojeriza ao seu ofício geracional; os agentes do Ibama sabem que não podem executar sua função de forma efetiva.

"Eu sou aquele que sempre quer fazer o mal, mas acaba fazendo o bem", assim se apresenta o protagonista do conto "A dócil", de Dostoievski, citando uma passagem de Goethe, Fausto, onde Mefistófeles se apresenta a uma outra personagem. No sistema de licenciamento, o que parece acontecer é o contrário, fica a sensação de que todos querem o "bem", mas acabam fazendo o "mal". Provavelmente se fosse entrevistar um membro do MP relacionado ao licenciamento seria relatado alguma forma de desesperança, alguma forma onde o (a) agente acharia que seu trabalho seria cerceado por algum outro agente.

Como que um procedimento que aos olhos de seus agentes se apresenta como tão falho e conflituoso pode parecer tão "anestesiado" pelo direito? Como que o direito naturaliza conflitos sem resolvê-los, simplesmente ignorando-os a partir da sombra do procedimento racionalmente elaborado?

A presente pesquisa acaba por suscitar um programa de pesquisa: i) como que o Direito ignora tão facilmente os conflitos sociais que deveria regular? Como funciona essa duplicidade de dimensões que as ciências sociais ajudam a desvelar? ii) Partindo dos problemas relatados nas pesquisas feitas e no trabalho de campo, como que os diversos agentes se relacionam?

Percebemos que as diversas associações de pescadores não acreditam no licenciamento ambiental como um procedimento apto a proteger a população afetada das externalidades negativas relacionadas ao empreendimento ao mesmo tempo que não preveem formas de realçar as externalidades positivas que poderiam compensar aquelas, mas como que as associações interagem entre si? $\mathrm{Na}$ audiência assistida pode ser dito que estariam presentes por volta de 20 associações relacionadas às populações tradicionais da região. Como elas se articulam ou não articulam para um eventual objetivo comum? Como que as associações de pescadores se associam às de populações remanescentes de quilombos, por exemplo? Será que o sistema de licenciamento agrega ou desagrega estes coletivos?

O estudo do conflito como um antídoto à anestesia jurídica

"You just a pawn in their game." (DYLAN, 1964) 


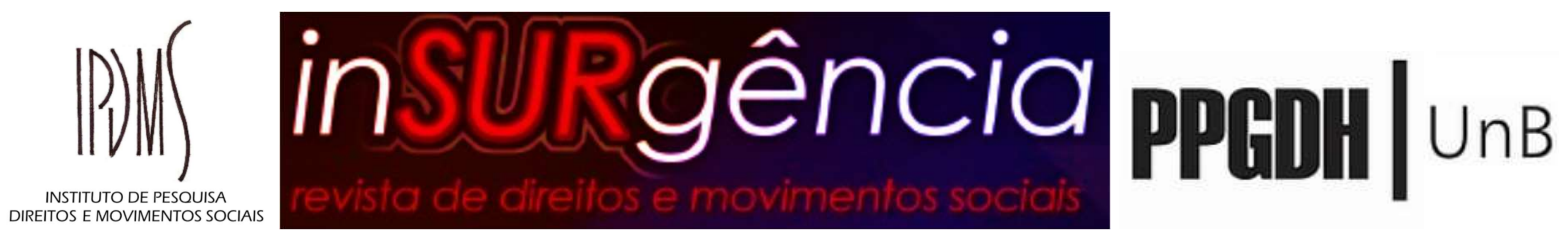

\section{BIBLIOGRAFIA}

ALEXANDER, Jeffrey. O novo movimento teórico. Revista Brasileira de Ciências Sociais. N.4, vol.2, 1987, pp-5-25

BRASIL. CONSTITUIÇÃO FEDERAL DE 1988. Disponível em: $<$ http://www.planalto.gov.br/ccivil_03/constituicao/constituicao.htm $>$. Acesso em 02 jun. 2019.

BRONZ, Deborah. Nos Bastidores do Licenciamento Ambiental: Uma etnografia das práticas empresariais em grandes empreendimentos. Rio de Janeiro: Contra Capa, 2016.

DRIVER, Taxi. Direção: Martin Scorsese. (113 min), Columbia Pictures, 1976.

DYLAN, Bob. Only a Pawn in Their Game. The times they are a-changing. Nova York, Columbia, 1964.

FOUCAULT, Michel. A verdade e as Formas Jurídicas. Rio de Janeiro: Nau Editora, 2002.

GUSTERSON, Hugh. Studying Up Revisited. Political and Legal Anthropology Review 20: 114-19, 1997.

NADER, Laura. Up the anthropologist: perspectives gained from 'studying up'. In: HYMES, D. Reinventing anthropology. New York: Random House, 1972. p. 284-311

'The vertical slice: hierarchies and children', in G.M.Britan and R. Cohen (eds) Hierarchy and Society. Anthropological Perspectives on Bureaucracy, Philadelphia: Institute for the Study of Human Issues. 1980

NEVES, Marcelo. (Não) Solucionando Problemas Constitucionais: Transconstitucionalismo Além de Colisões. Lua Nova, São Paulo, 93: 201-232, 2014.

ORGANIZAÇÃO DAS NAÇÕES UNIDAS. Assessing Environmental Impacts - A Global Review of Legislation. Disponível em: $<$ https://europa.eu/capacity4dev/unep/documents/assessing-environmental-impacts-globalreview-legislation> Acesso em 22 ago. 2019

SANTOS, A.F.M.; FERREIRA, L. S. S. ; PENNA, V. V. . Impactos supostos, violências reais: a construção da legalidade na implantação do Projeto Minas-Rio. In: Andréa Zhouri. (Org.). Mineração: violências e resistências: um campo aberto à produção de conhecimento no Brasil.. 1ed.Marabá/Brasília: Editorial iGuana/ABA, 2018, v. , p. 176-220.

TAUSSIG, Michael. Walter Benjamin's Grave. Chicago: The University of Chicago Press, 2006.

TROUILLOT, Michel-Rolph. Global Transformations: Anthropology and the Modern World. Nova Iorque: Palgrave Macmillan, 2011.

VON FOERSTER, H. 1981. “On constructing reality”. In: VON FOERSTER, H. Observing systems. Seaside: Intersystems Publications, pp.

288-309

WRIGHT, Susan. The Anthropology of Organizations. Londres: Routledge, 1994. 